\title{
Bending Response and Energy Absorption of Closed-Hat-Section Beams
}

\author{
Hafizan Hashim ${ }^{1}$, Amir Radzi Ab Ghani ${ }^{1} \&$ Wahyu Kuntjoro ${ }^{1}$ \\ ${ }^{1}$ Faculty of Mechanical Engineering, Universiti Teknologi MARA, 40450 Shah Alam, Selangor, Malaysia \\ Correspondence: Hafizan Hashim, Faculty of Mechanical Engineering, Universiti Teknologi MARA, 40450 \\ Shah Alam, Selangor, Malaysia. Tel: 6-019-649-2305. E-mail: hafizandes@gmail.com
}

Received: June 18, 2016

Accepted: July 18, 2016

Online Published: August 18, 2016

doi:10.5539/mas.v10n11p225

URL: http://dx.doi.org/10.5539/mas.v10n11p225

The research is financed by Ministry of Education, Malaysia (MOE).

\begin{abstract}
Many articles on bending collapse but not limited to closed-hat-section beams have been reported mainly from experimental point of view but less in simulation-based approach. Detailed investigation on critical parameters of closed-hat-section beams to examine their energy absorption capability is also less found in the literature. This paper presents the procedure for development and validation of a finite element (FE) model of a closed-hat-section beam under quasi static three-point bending using an explicit nonlinear FE technique. Developed FE models were validated through comparison with existing and present experiment results. Firstly, the existing models were rebulit via present modeling technique using informations provided in the relevant research report. Simulation results of rebuilt model were compared with existing results for verification and validation. Next, to further validate the present model, actual physical experiment replicating the FE model was set up for comparison of results. Validated models were then used in parametric studies in order to investigate the effect of some critical parameters such as plate thickness, flange and web width, and foam filler. Results show that the wall thickness, web width, and filler have direct effect on bending stiffness. Foam filling indicated significant enhancement on the crush and energy absorption of closed-hat-section beams. This study provides detail procedures and research information which will facilitate improvisation of current design as well as the design of foam filled closed-hat-section beams as energy absorbers in impact applications.
\end{abstract}

Keywords: bending, hat-section, quasi-static, finite element

\section{Introduction}

In order to remain competitive with new alternative materials, a good understanding of the collapse behavior of closed-hat-section beams is essential particularly for automotive structural applications. This would allow enhancement of the development mathematical models to be made, which would take into account the effect of extended flange and closed-plate. Physical experiment provides information and knowledge of collapse behavior with actual condition and truly reliable. However, for optimization of one design, repetitive experiments are considered non-economical for it may requires the use of quite number of test specimens. Here, the role of FEA becomes a tremendous productivity tool, resulting in overall cost and time reduction.

Among famous articles reported about theoretical bending collapse of rectangular tubes with analytical approach were made by Kecman (1983), Wierzbicki et al. (1994), and Kim \& Reid (2001). Here, only Wierzbicki et al. used FE simulation to validate the analytical model. Thereafter, analytical model developed by Wierzbicki et al. was criticized by Kim \& Reid (2001) since it was irreproducible. Cimpoeru \& Murray (1993) experimentally studied the moment-rotation properties of square tubes under large deflection pure bending and the results acquainted with Kecman (1983). Even though Kecman's theory (Kecman, 1983) is not kinematically admissible as one proposed by Kim \& Reid (2001), it suits well with most of the experiment and simulation works done later. Chen (2001) studied experimentally the crushing behavior of empty and foam-filled aluminum closed-hat-section and double hat-section under three-point and deep bending. FE models replicate actual experiment were developed and validated well. Chen's article (Chen, 2001) provides information in quite detail and has been used by author to compare the FE results through model replication. A similar study was reported 
by Santosa et al. (2001) in their work to investigate the bending response of fully and partially filled beams experimentally and numerically. Closed cell aluminium foam was used as a filler and it presence has increased the bending resistance significantly as expected. Same results were reported for partially filled beam which indicate potentiality of lighter foam filled energy absorber. Later work by Chen et al. (2002) which could be considered a continuity from Santosa et al. had focused on comparing the strengthening effect of foam and honeycomb filler on the plastic resistance during bending collapse. The moment resistance from honeycomb filling is larger than that of foam, however, honeycomb material is very orthogonal that depends too much on the loading direction, not like the foam which is more isotropic.

A companion study on closed-hat-section was reported by Bambach et al. (2009) who experimentally studied the influence of perforations at the compression flange on moment-rotation relation when subject to large pure bending. An empirical procedure was developed to determine the large deformation bending but no numerical approach was reported. Another study on the bending crush performance of closed-hat-section was reported by Belingardi \& Scattina (2013). The aim was to evaluate the adhesion strength of closed-hat-section jointed by structural adhesive and spot weld. Hybrid composite-metal specimens which were jointed using adhesive absorbed highest energy, followed by full metal spot-welded and lastly the fully composite hat-section. Results demonstrate the advantages of utilizing adhesive for structural joining to reduce weight. This study however was purely experimental.

A review of literature showed that many articles on bending collapse but not limited to closed-hat-section have been published mainly from experimental point of view but less in simulation approach. Most of the tubes and beams involved in the existing literature are of aluminium extrusion type closed section. This paper presents FE model development using ABAQUS with validation procedures for closed-hat-section beams subject to three-point bending. The developed explicit non-linear FE model went through two types of validation procedures which are from existing results and present physical experiments. Simulation results are compared with existing and present testing results showing good agreement. Validated models were then used in parametric studies to investigate the effect of some critical parameters such as plate thickness, flange and web width, and foam filler. Foam filling indicated the most significant enhancement on the crush and energy absorption of closed-hat-section beams compared to wall thickness, web, and flange width. This study provides detail procedures and research information which will facilitate improvisation of current design of closed-hat-section beams as well as the design of foam filled closed-hat-section beams as energy absorbers in impact applications.

\section{Energy Absorption Performance Indices}

Crashworthiness of a structure is defined as the ability to absorb the impact energy and thereby bringing the vehicle to rest without the occupant being subjected to high or sudden deceleration. It is expressed in term of specific energy absorption (SEA), $E_{s}$ which is the ratio of energy absorbed to the unit mass of the material;

$E_{s}=W / V \rho(1)$

where $W=$ total energy absorbed

$V=$ volume of material

$\rho=$ density of material.

\section{Computer Modeling and Development of FE Model}

\subsection{Specimen / Model Geometry and Finite Element Mesh}

A closed-hat-section beam is a combination of a hat-section and a closed-plate. For present experiment, both parts were drilled and bolted together to form a closed-hat-section. This type of connection becomes useful when the overall thickness increase. Beam was modeled using robust conventional shell elements, S4R, which is a four-noded quadrilateral element with six degrees of freedom per node while the indenter and rigid support were modeled using R3D4 rigid elements. S4R is suitable for large strain analyses with ability to enhance hourglass
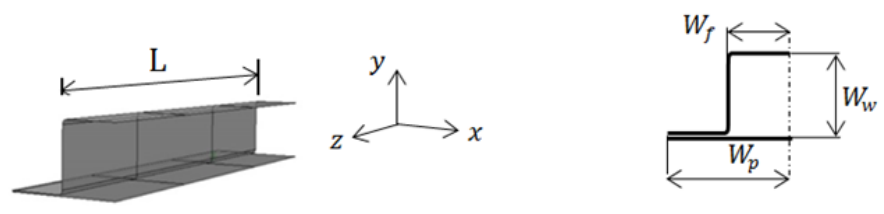

Figure 1. Half model geometry of the closed-hat-section beam 
Table 1. Design dimensions of the closed-hat-section beam (Half model, Unit: $\mathrm{mm}$ )

\begin{tabular}{llllllll}
\hline Specimens & Section & $L$ & Web, $W_{w}$ & Flange, $W_{f}$ & Plate, $W_{p}$ & Span & $t$ \\
\hline 1) QS_H0_1 & Hat & 300 & 15 & 30 & - & 250 & 1 \\
2) QS_H0_2 & Closed plate & 300 & - & - & 60 & 250 & 1 \\
3) QS_H0_3 & & & & & & \\
\hline
\end{tabular}

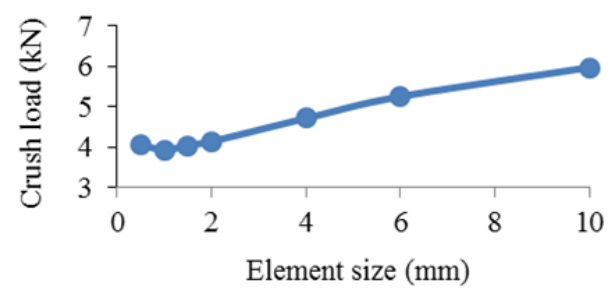

Figure 2. Mesh convergence of S4R element for closed-hat-section beam

control. To allow nonlinear material behavior, five integration points was employed through the shell thickness. From detail observation of the preliminary simulation, the deformation mode of full and half model can be treated symmetrically. Therefore half models were used to reduce the number of degrees of freedom (DOFs) and computational time as shown in Figure 1. Table 1 tabulates design dimensions of the beam.

\subsection{Mesh Convergence Study}

The most fundamental in constructing an accurate FE model are the correct element type and its required smallness. This can be achieved through mesh discretization method where number of elements are recorded and compared as implemented by Koslan et al. (2013) and Amir et al. (2013). Figure 2 shows maximum indentation force versus element size in the refined mesh of hinge region. The crush load converged as the mesh density increased. Therefore the element size of $2.0 \times 2.0 \mathrm{~mm}$ is chosen to model the hinge region, while the rest of parts with a size of $5.0 \times 2.0 \mathrm{~mm}$ (Chen, 2001). To avoid an infinite stress, a radius of $2 \mathrm{~mm}$ at each flange's corner was introduced and based on the convergence study the radius size is reasonable as well as number of elements spaced around the corner area.

\subsection{Loading, Interaction, and Boundary Condition}

The indenter is described as a rigid surface translates only along the y axis as shown in Figure 3. The beam specimen is supported by a simple supporting system which is fully constrained (i.e., $\mathrm{U} 1=\mathrm{U} 2=\mathrm{U} 3=\mathrm{UR} 1=\mathrm{UR} 2=\mathrm{UR} 3=0$ ) to avoid relevant geometric or dimensional change. Here, U1, U2, and U3 are linear displacement while UR1, UR2, and UR3 are rotation about $x, y$, and $z$ axis respectively. Indenter and rigid supports are tagged by a reference node each to ease control on the motion of the body as a whole. Due to mirror symmetry, boundary conditions along free edges of beam are applied symmetrically constraining U1, UR2, and UR3. Other important aspect in modeling would be the size of the step time. This parameter is essential for the convergence of the values as well as the total time of the simulation. For quasi-static nonlinear crushing analysis, the step time is determined from a FREQUENCY linear perturbation analysis step which is provided in ABAQUS/Standard (ABAQUS 6.13 User's Manual, 2013). In this study, the step time was determined at $0.03 \mathrm{~s}$. In an explicit impact analysis, the step time represents the actual impact duration. For a smooth indentation, the motion of the indenter was simulated using the SMOOTH STEP sub-option of the AMPLITUDE option.
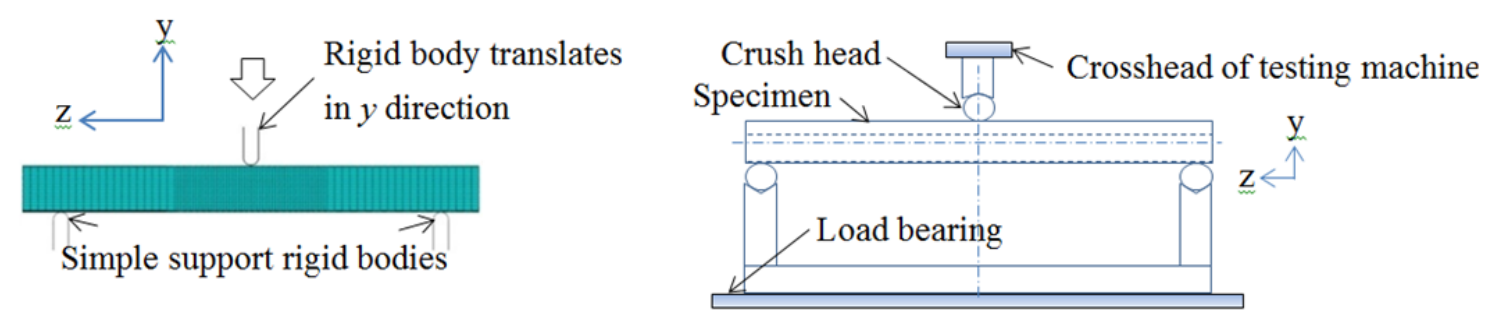

Figure 3. A FE mesh of the full model subject to three-point bending 


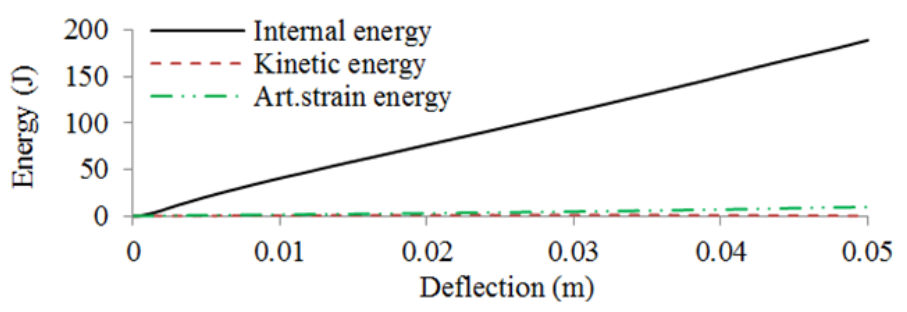

Figure 4. A FE mesh of the full model subject to three-point bending

This option can avoid inaccurate results caused by system noise and at the same time enable user to control the motion of the indenter so it can travels over required time duration as prescribed in the total step time (ABAQUS 6.13 User's Manual, 2013). In modeling contact, the highly automated contact algorithm which includes all surface definition was used for the whole system. The finite sliding "penalty" based contact algorithm with contact pairs and "hard" contact were used to define the self-contact between the beam walls during collapse, and surface-to-surface contact between each rigid surface and the beam. All surface contact in the present finite element models was treated with 0.25 friction coefficient except those contacted with rigid surfaces which was treated as frictionless.

For an acceptable quasi static result, the kinetic energy of the deforming part should not exceed a small fraction of its internal energy throughout the majority of the analysis, typically 1-5\% (ABAQUS 6.13 User's Manual, 2013). This is because the indenter is massless and so the only kinetic energy is carried by the beam. Figure 4 shows the energy plot of quasi-static simulation of the beam. It clearly shows that the maximum kinetic energy is sufficiently small compared with the internal energy. It also shows both the kinetic and internal energy-time profiles are smooth which indicates that no significant plasticity behavior which could affect the solution. To ensure hourglass is minimized, the ratio of artificial strain energy to internal energy was investigated and found to be less than $5 \%$.

\subsection{Mesh Independent Spot Weld}

In this study, mesh-independent spot weld was used to model rigid spot weld which do not fail under any circumstances. The principal advantage of using mesh-independent spot welds instead other connections methods is that the parts that are to be connected can be meshed independently of their assembly, later the spot welds can be located by specifying a single coordinate point near to the surfaces of the parts, thus the locations of the spot welds can be independent of the locations of the nodes on both sides of the connection. The size of the region of influence can be modified by changing the radius of influence. In this work, the radius of influence was chosen to be equal to the physical hole radius which is $3 \mathrm{~mm}$.

\subsection{Material Model}

The beam was modeled with a piecewise linear elastic-plastic material model with strain hardening. Material coupon tensile test was conducted using the Instron model 3382 Universal Testing Machine (UTM). The material properties for the mild steel are as follows: initial yields stress; $\sigma_{y}=340 \mathrm{MPa}$, Young's modulus; E=200 GPa, Poisson ratio; $v=0.3$, Ultimate Tensile Strength (UTS); $\sigma_{u}=391 \mathrm{MPa}$, and density; $\rho=7809 \mathrm{~kg} / \mathrm{m}^{3}$. The engineering stress-strain curve of the material was obtained using a standard tensile test in accordance with AS1391-1991(1991). Figure 5 shows the true stress-strain curve from coupon tensile test. From this curve, the approximated data points which are used in the FE models are tabulated in Table 2. The ancillary strain data was converted into true strain by using;

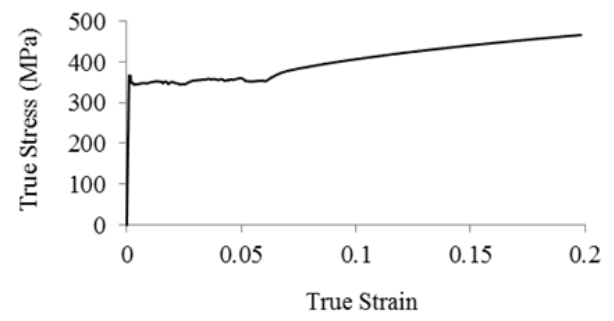

Figure 5. A FE mesh of the full model subject to three-point bending 
Table 2. Approximated true stress-plastic strain data points for the FE model

\begin{tabular}{ccccccc}
\hline$\sigma_{t}\left(\mathrm{~N} / \mathrm{mm}^{2}\right)$ & 340.40 & 354.21 & 398.41 & 425.02 & 446.21 & 462.10 \\
\hline$\varepsilon_{p}$ & 0 & 0.0613 & 0.0900 & 0.1251 & 0.1600 & 0.1900 \\
\hline \multicolumn{6}{c}{$\varepsilon_{\text {true }}=\ln (1+\varepsilon)$} & \\
\end{tabular}

where, $\varepsilon=$ experimental strain. The true stress data was converted using;

$$
\sigma_{\text {true }}=\sigma \cdot(1+\varepsilon)
$$

where, $\sigma=$ experimental stress.

\section{FE Validation against Existing and Present Results}

\subsection{Rebuilding of Existing Model for Validation of the Present Modeling Technique}

The International Journal of Solids and Structures is one of the strong sources of relevant literature in the field of structural mechanics. A published article by Chen (2001) contains many relevant works to the present study like the similar cross section and boundary condition which provide worthwhile reading and reference. In the previous study, Chen (2001) used a high strength aluminium alloy of variant AA5754 to produce the closed-hat-section specimens. The true stress-strain curve of the alloy is shown in Figure 6. In the present work, author managed to remodel the specimen and the experimental setup using present FE modeling approach. This is to verify whether the FE remodel capable to replicate and predict the experimental behavior of Chen (2001) and thus validate the FE remodel. In addition, the FE remodel was also compared with Chen (2001) FE model that was developed parallel to his experiment work. Figure 7 shows half cross section geometries of conventional and double-hat-section beams used by Chen (2001). The double-hat-section had also been considered for remodeling to be more convincing of the present modeling technique. Details about section dimensions are listed in Table 3. The mesh, loading, and boundary conditions are all follow Chen (2001) model. Type and element designation were the same used in the present FE model as well as the $25 \mathrm{~mm}$ pitch spot welds. For information, Chen (2001) utilized a non-linear explicit code PAM-CRASH throughout his simulation.

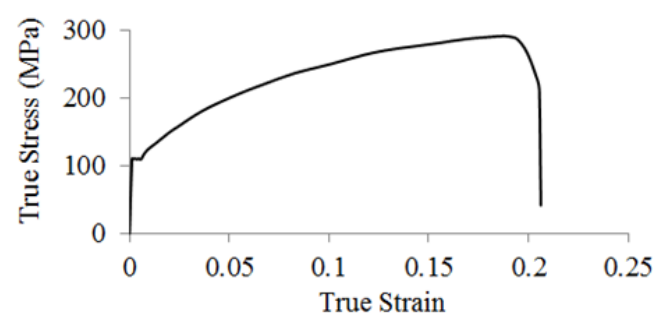

Figure 6. Stress-strain curves of aluminum alloy HS5754 (Chen, 2001)

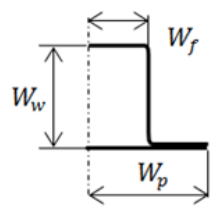

(a)

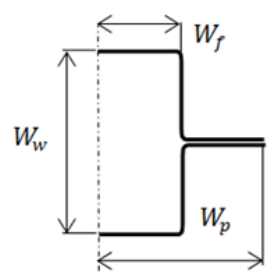

(b)

Figure 7. Half geometry of (a) closed and (b) double hat-section (Chen, 2001)

Table 3. Measured half geometry of section dimensions (Unit: $\mathrm{mm}$ ) (Chen, 2001)

\begin{tabular}{lcccccc}
\hline Specimens & $L$ & Web, $W_{w}$ & Flange, $W_{f}$ & Plate, $W_{p}$ & Span & $t$ \\
\hline Closed-hat-section & 675 & 25 & 12.50 & 23 & 550 & 2 \\
Double-hat-section & 675 & 52 & 12.75 & 23 & 550 & 2 \\
\hline
\end{tabular}




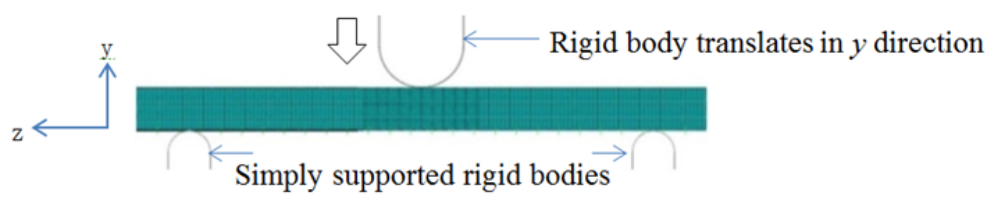

Figure 8. A FE mesh of Chen's remodel under three-point bending (Chen, 2001)

\subsection{Quasi static Experimental Testing for Validation of the Closed-hat-section Beam Model}

Three-point bending experiment was carried out to validate the present FE model. Beam geometry and dimensions are shown in Figure 1 and Table 1 respectively. Three specimens were fabricated to ensure repeatability and reducing the number of experiments. Quasi static tests were performed using Instron 3382 Universal Tensile Machine (UTM). Specimen is positioned between the indenter and two simple round supports as shown in Figure 3(b).

\section{Validation Results}

\subsection{Remodelling Results of Closed-hat-section Beams under Quasi Static Three-point Bending}

Figure 9 shows comparison of quasi static load and mean load-deflection curves between present remodel and Chen (2001). Figure 9(a) is referred, after the indenter crushing the beam center, there were forces that abruptly increased to a peak of just fewer than 8 and $7 \mathrm{kN}$ for both experiment and simulation. Just after the peak, both forces were slowly decreased to almost half of their peak load. As shown in Figure 9(b), both mean loads increased to a peak point before they were leveled off throughout the indentation process. The mean load was calculated by dividing the energy absorbed by the crush distance. The energy absorbed was obtained by integrating the crush load with respect to crush distance using functions in MATLAB. On average the difference is within $\pm 6.5 \%$.

Figure 10 shows the comparison result of present FE remodel and Chen's simulation. Both are generally similar in the initial prediction but slightly deviated towards the end. This is possibly due to the effect of curve fitting technique employed on both graphs. The deformation mode predicted by the present FE remodel compared well with experimental results as depicted in Figure 11. Figure 12 shows comparison result of quasi static load and

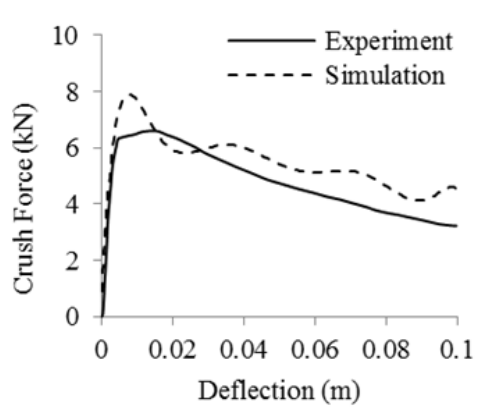

(a)

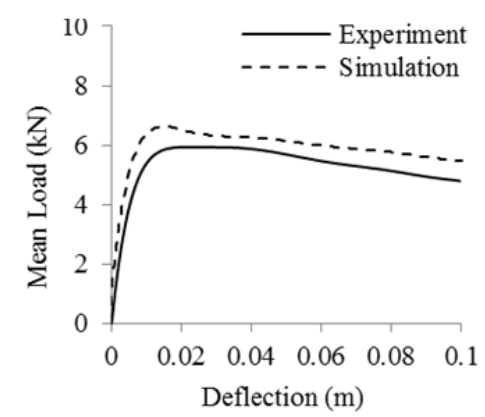

(b)

Figure 9. Comparison of quasi static (a) load and (b) mean-load deflection curves between present FE remodel and Chen (2001)

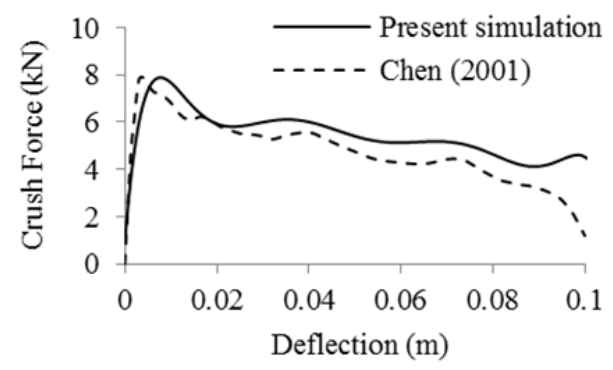

Figure 10. Comparison of present remodel and existing simulation results (Chen, 2001) 


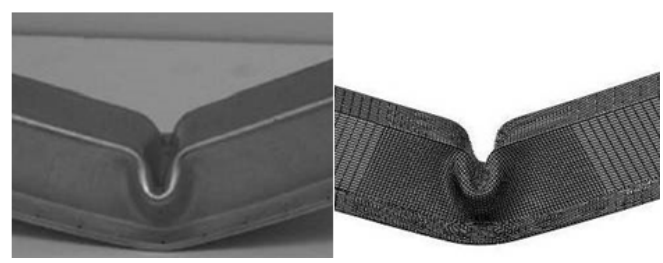

(a)

(b)

Figure 11. Comparison of collapse modes of a closed-hat-section beam from (a) existing experiment and (b) present remodel

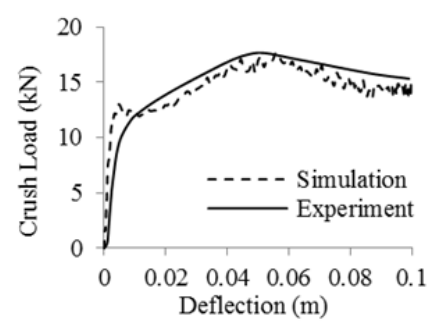

(a)

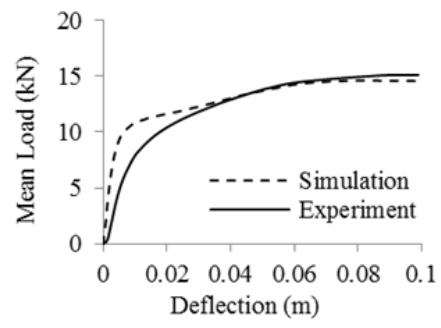

(b)

Figure 12. Comparison of quasi static (a) load and (b) mean load-deflection curves between present FE remodel and existing experimental results for double hat-section (Chen, 2001)

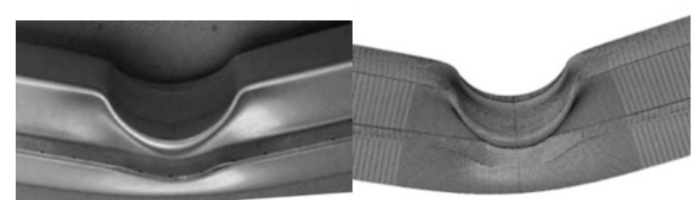

(a)

(b)

Figure 13. Comparison of collapse mode of a double hat-section from present FE remodel and existing experimental results (Chen, 2001)

mean-load deflection curves between present FE remodel and existing experimental results for double hat-section. Good agreement is seen between FE remodel and experimental results for both curves as well as the collapse mode as shown in Figure 13. As a whole, results from FE remodel demonstrate a reasonable agreement with Chen experimental data (Chen, 2001).

\subsection{Validation Results of Present FE Model against Three-point Bending Experiment}

Again, the quasi static three-point bending results demonstrate a reasonable agreement, this time between present FE model and experimental data. Figure 14 shows comparison of load-deflection curves between present model and experiment. During inital crush, there were forces that abruptly increased to a peak of approximately $5 \mathrm{kN}$ for FEA and $4 \mathrm{kN}$ for the experiment result. Just after the peak, both forces were gradually decreased

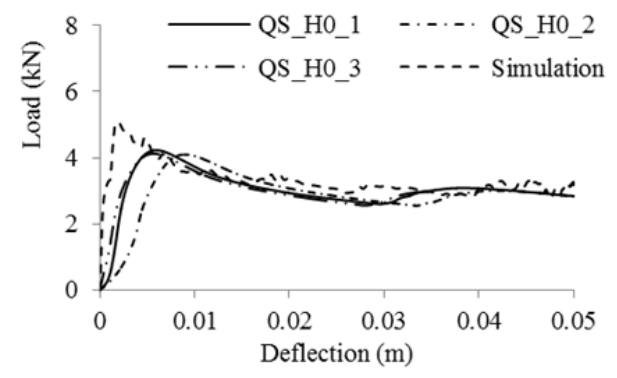

Figure 14. Quasi static load-deflection for closed-hat-section beams (FEA vs. Experiment) 


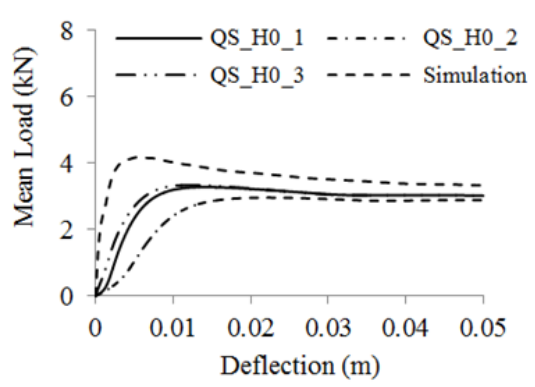

(a)

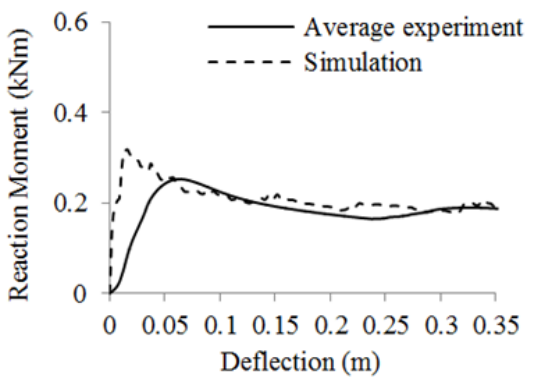

(b)

Figure 15. (a) Mean load-deflection and (b) Moment-rotation curves for closed-hat-section beams (FEA vs Experiment)

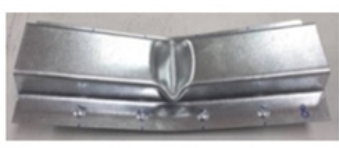

(a)

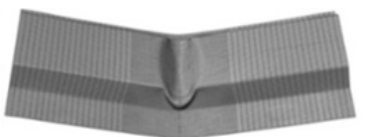

(b)

Figure 16. Comparison of collapse mode of closed-hat-section beam between (a) experiment and (b) present simulation

before leveling off with little fluctuation throughout the indentation. Figure 15(a) shows comparison of mean load-deflection curves between present FE model and experiment. FE model output and measured output are broadly similar with average difference within $5 \%$. The deformation mode predicted by the FE model also compared well with present experiment result as depicted in Figure 16.

\subsection{Effect of Thickness}

Comparison of quasi static load and mean load-deflection responses as the wall thickness increases for conventional closed-hat-section (H0) beam when subjected to three-point bending are shown in Figure 17. Mean load is the average load indicates measured load at any particular deflection by dividing the energy absorbed over deflection. In this figure, a mean load curve is plotted by using several values of the mean or average load calculated from a set of load deflection data. Thicker plate thickness contributes to a significant increase in the mean load up to a given deflection. It is worth noting that at 1.5 and $2 \mathrm{~mm}$ thickness, the mean load of the H0 increases dramatically up to double and over triple till the end of bending deflection of the crush distance. This could possibly due to the compaction of the folds and the densification of the hinge region under compression loading. In similar fashion, as the plate thickness increases, the energy absorbed as well as the SEA increase up to a given deflection as plotted in Figure 18 and 19. Thicker plate provides more material for plastic deformation, subsequently increase the energy absorption capacity with increasing deflection. Figure 20 shows deformed shape of $\mathrm{HO}$ at various wall thicknesses. Stress area increases by the increase of wall thickness. Obviously, the energy dissipation of $\mathrm{H} 0$ beams is significantly affected by increasing the wall thickness.

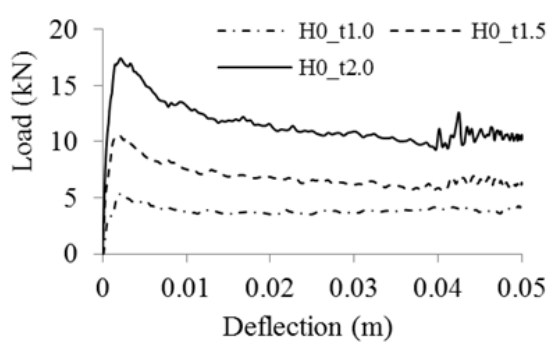

(a)

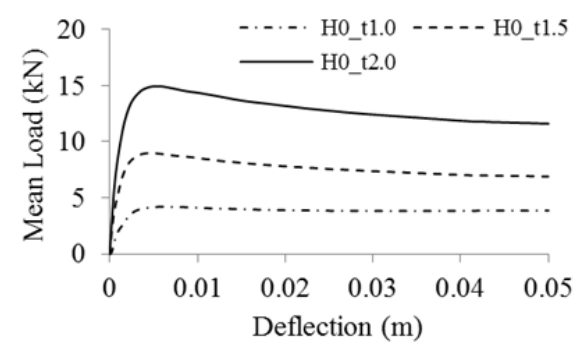

(b)

Figure 17. Effect of wall thickness on (a) load and (b) mean load-deflection curves 


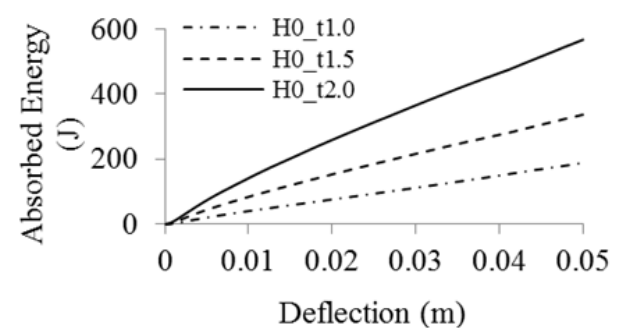

Figure 18. Effect of wall thickness on energy absorption

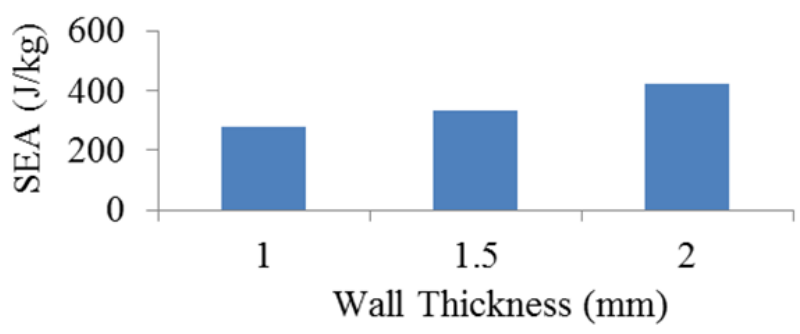

Figure 19. Specific energy absorption (SEA) at various wall thicknesses

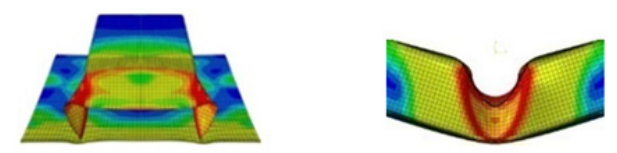

$\mathrm{H} 0(\mathrm{t}=1.0 \mathrm{~mm})$

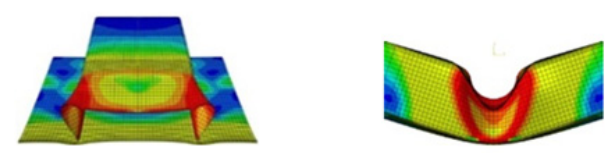

$\mathrm{H} 0(\mathrm{t}=1.5 \mathrm{~mm})$
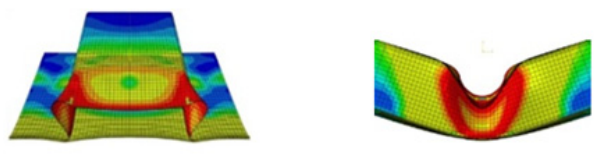

$$
\mathrm{H} 0(\mathrm{t}=2.0 \mathrm{~mm})
$$

Figure 20. Deformed shape of closed-hat-section at various wall thicknesses

\subsection{Effect of Web and Flange Width}

Under three-point bending, the web section will be the first to buckle before hinge line is created. Since the energy absorption response could be influenced by the size of the web section, the effects of varying the web width at $20 \mathrm{~mm}, 30 \mathrm{~mm}$, and $40 \mathrm{~mm}$ were studied with constant $1 \mathrm{~mm}$ plate thickness and $60 \mathrm{~mm}$ flange width. Figure 21 shows the load and mean load-deflection responses from different web width. For H0 type beam, it can be seen that the web width affects significantly the mean load-deflection response at the width of $30 \mathrm{~mm}$. However, increasing the web width to $40 \mathrm{~mm}$ has only increased the mean load by $0.5 \mathrm{kN}$ which is less significant compared to the previous increase of $30 \mathrm{~mm}$. The findings are similar as what were presented by Amir et al. (2013) during the investigation of the effect of groove depth on square beams with U-shape grooves. On the other hand, increasing the flange width surprisingly does not increase the load as the deflection increases as shown in Figure 22. 


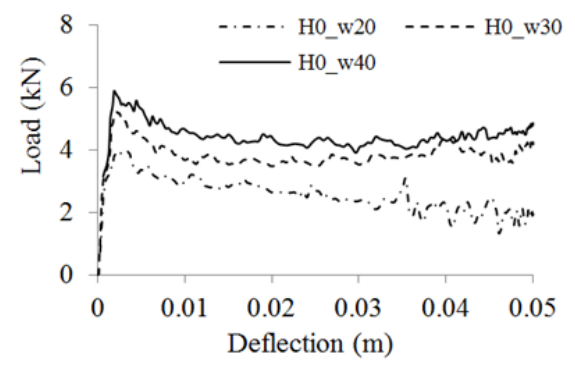

(a)

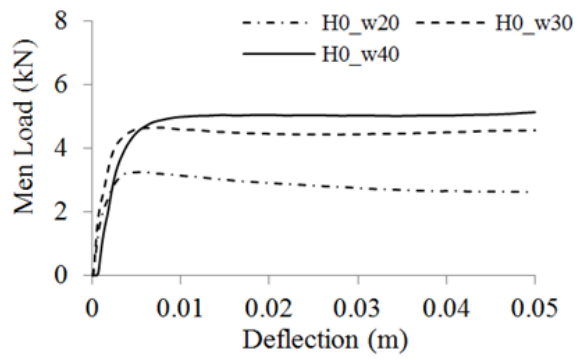

(b)

Figure 21. Effect of web width on (a) load and (b) mean load-deflection curves

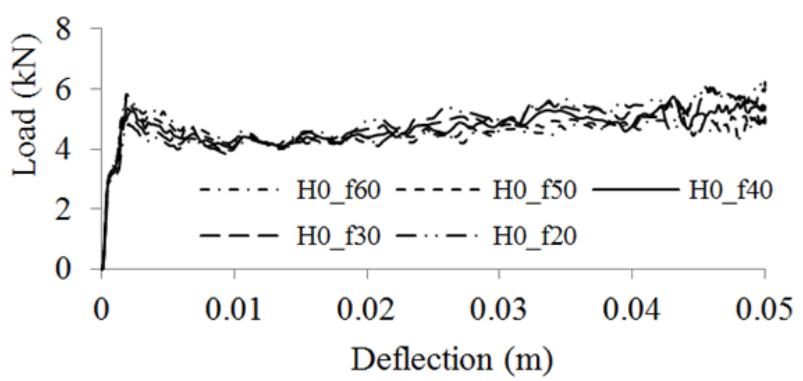

Figure 22. Effect of flange width load-deflection curves

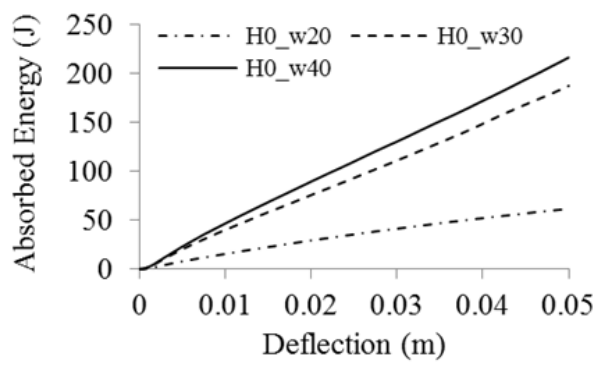

(a)

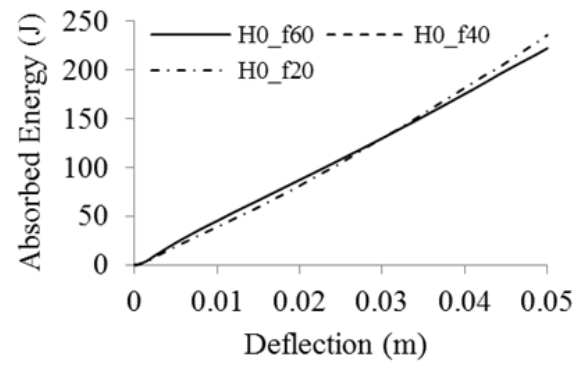

(b)

Figure 23. Effect of (a) web and (b) flange width on energy absorption

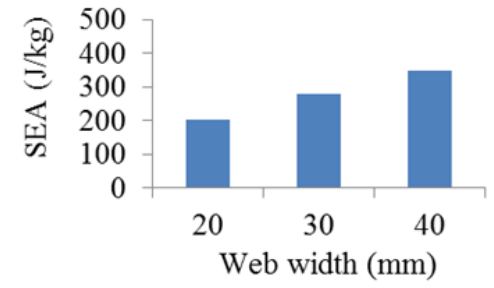

(a)

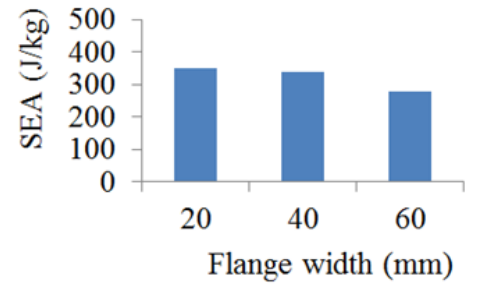

(b)

Figure 24. Specific energy absorption (SEA) at various (a) web and (b) flange width

In terms of energy absorption response, the effect of web width is quite similar to the aforementioned response of the mean load, as the mean load is always related to the energy absorbed. Figure 23 shows the effect of the web and flange width on the absorbed energy of the H0 beams under quasi static three-point bending. In general, the energy absorbed is slightly increases when introducing a wider web width. It is contradict with varying the flange width where amount of energy absorbed is almost unchanged. For the SEA, similar response can be seen as shown in Figure 24. It can be concluded that, varying the web width has more significant effect on energy absorption and SEA than the flange width, however due to the balance response with minimal fluctuations, wider 
flange width can offer higher cushioning effect which is more forgiving for low to medium velocity and small inertia impact for instance in motorcycle crash barrier application. Figure 25 and 26 show the deformed shape of $\mathrm{H} 0$ at various web and flange width.
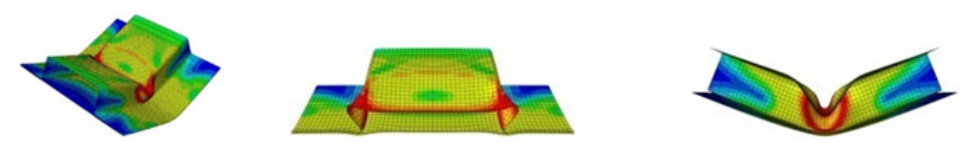

$\mathrm{H} 0\left(W_{w}=20 \mathrm{~mm}\right)$
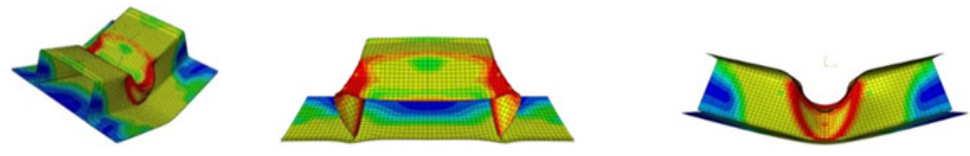

$\mathrm{H} 0\left(W_{w}=30 \mathrm{~mm}\right)$
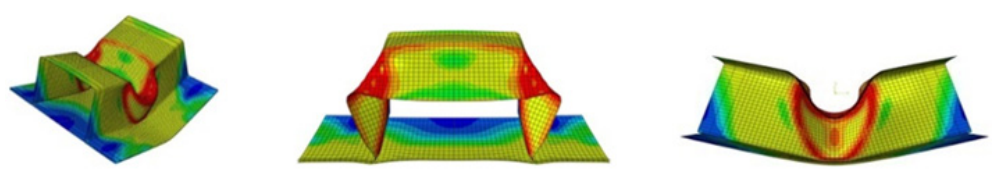

$\mathrm{H} 0\left(W_{w}=40 \mathrm{~mm}\right)$

Figure 25. Deformed shape of closed-hat-section at various web width (constant $t, W_{f}$ )
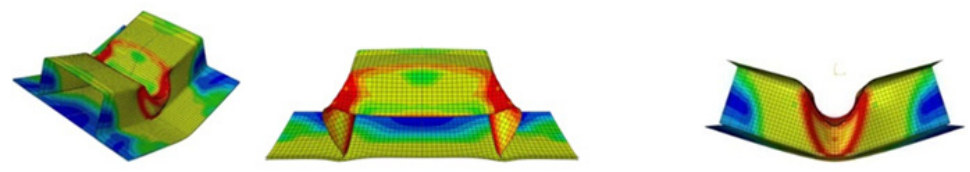

$\mathrm{H} 0\left(W_{f}=60 \mathrm{~mm}\right)$
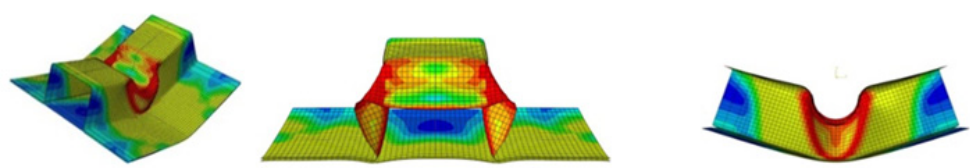

$\mathrm{H} 0\left(W_{f}=40 \mathrm{~mm}\right)$
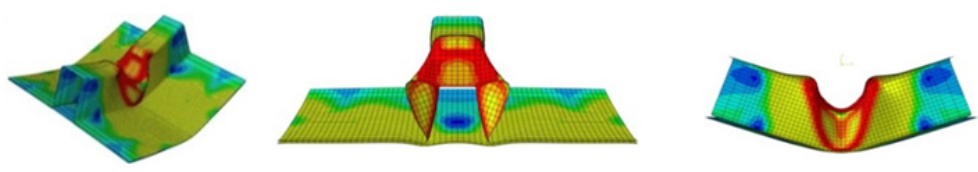

$\mathrm{H} 0\left(W_{f}=20 \mathrm{~mm}\right)$

Figure 26. Deformed shape of closed-hat-section at various flange width (constant $t, W_{w}$ )

\subsection{Effect of Foam Filled}

The aluminium foam used in this study was adopted from Chen (2001) and the stress-strain relationship for the foam was derived from compression test as shown in Figure 27. Graphs show typical stress-strain plot for a closed-cell aluminium. The first is a roughly linear elastic regime. This is followed by a long stress-plateau where the stress remains nearly constant and then truncated by a densification response, where the stress again increase steeply. The mechanical properties of foam are highly dependent on the relative density of the foam material. For this study, the beams were fully filled and partially filled in the center by one third of its total length. The same approach was implemented by Santosa et al. (2001) in the previous work. 


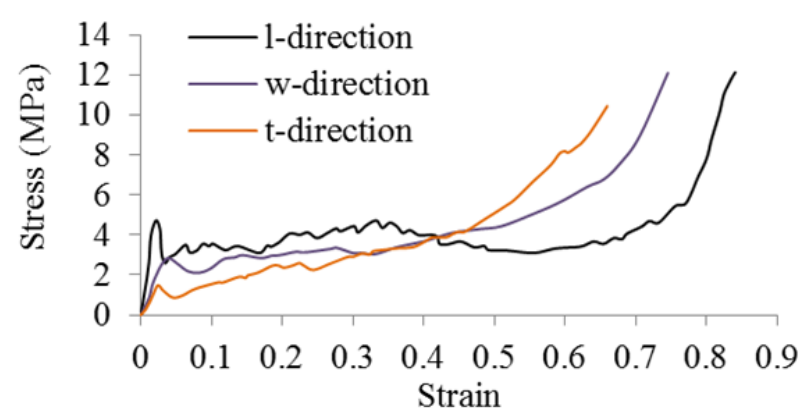

Figure 27. Stress-strain curves of aluminium foam $\left(0.27 \mathrm{~g} / \mathrm{cm}^{3}\right)$

Figure 28 shows load and mean load-deflection responses for empty and foam filled H0 under quasi static three-point bending. A previous study by Santosa et al. (2001) indicated that friction between the side wall and foam material had little effect on the deformation pattern or mean-load. For the present simulation, contact between foam and beam's wall was defined as frictionless. Results reveal that the presence of foam filler has significant effect on the load and mean load-deflection responses by approximately half of the empty beam. The load and mean load were slightly increased towards the end of indentation due to the densification effect of the filler. Figure 29 shows that the filled beam improved the performance indicator, SEA for about $58 \%$ compared to empty beam. The SEA can be furher improved by optimizing the length of filled filler in order to minimize the weight.

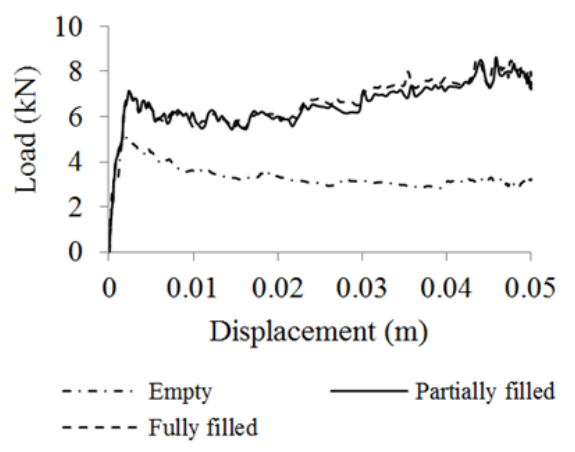

(a)

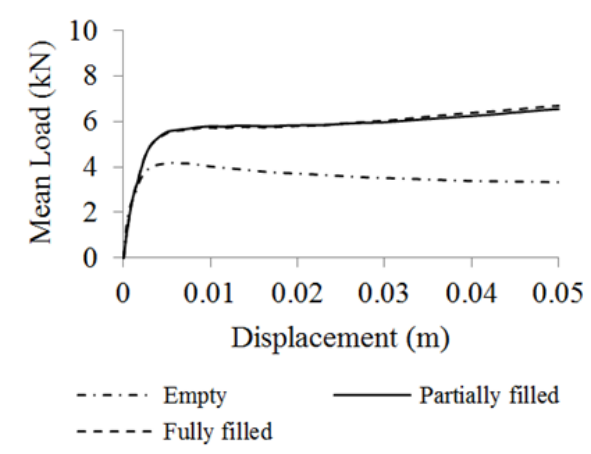

(b)

Figure 28. Effect of foam filled on (a) load and (b) mean load-deflection

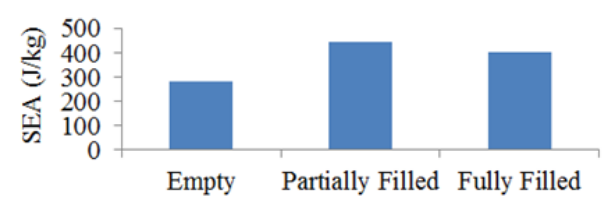

Figure 29. Comparison of SEA for empty, partially filled, and fully filled H0 beams 

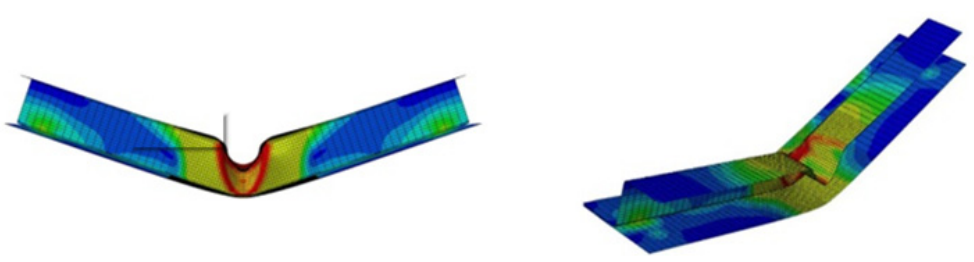

(a) Empty $\mathrm{H} 0$ beam

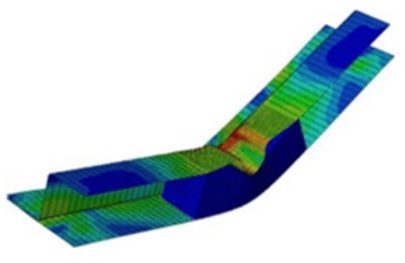

(b) Partially foam filled $\mathrm{H} 0$ beam
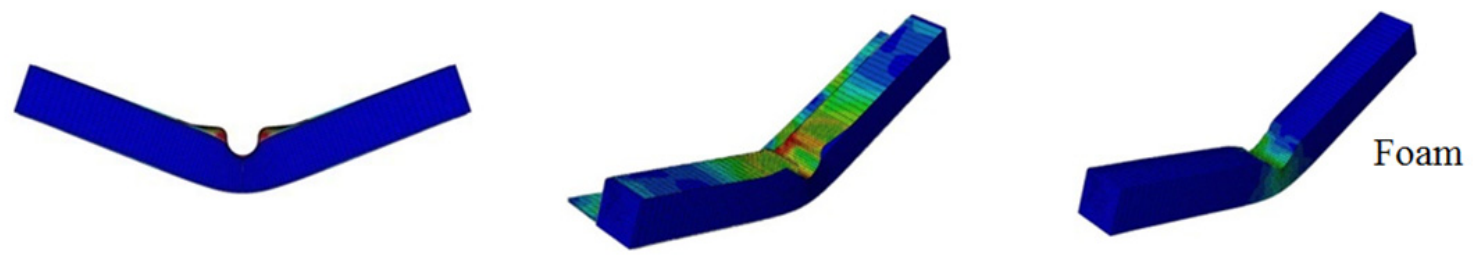

(c) Fully foam filled H0 beam

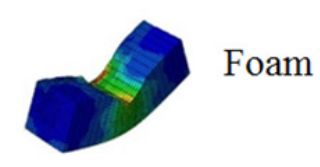

Foam

Figure 30. Deformed shape of (a) empty, (b) partially foam filled and (b) fully foam filled closed-hat-section beam

Figure 30 shows the deformed shape of empry and foam filed H0 beam. The presence of foam filler has slightly shortens the fold length, resulting in folds of larger curvature. Based on the present observation, the numbers of folds are expected to increase if the filled beams went under deep bending which exceed present indentation depth. More fold means more plastic deformation can occur thus acquire more loads and subsequently improve the SEA.

\section{Conclusion}

Quasi-static experimental three-point bending tests and model replication and rebuilding on conventional closed-hat-section beams have been conducted. Present FE model was successfully validated using existing model replication and physical experiment. To further details on the bending behavior, parametric studies on some critical parameters via simulation were performed using explicit FE code ABAQUS. Parameters in FE simulation include wall thickness, flange and web width, and foam filler. The results reveal the following:

1) Increasing wall thickness has significant effect on the load-deflection response. Thicker wall means more material for plastic work, indirectly means higher bending stiffness thus require higher force for bending. Thicker wall however, affects mass and volume of the beam which is undesirable and it does not reflect directly to the amount of energy absorbed.

2) For $\mathrm{H} 0$ beam with equivalent cross sectional area, increasing the web width gives more loading effect than the flange width. However for greater cushioning effect, wider flange width is desirable since wider flange does not affect the load characteristic significantly thus suitable for containing small inertia effect.

3) The presence of foam filler improved the SEA significantly by shortening the fold length for larger folding curvature allowing more plastic deformation to occur. Without sacrificing the mass and volume, filled beam is considered the best among other $\mathrm{H} 0$ beams.

4) Partially filled beam can be considered working effectively as well as fully filled beam. Partially filled beam is lighter than the fully filled beam but may require optimization on the filled length in order to improve the 
cost and efficiency.

\section{Acknowledgments}

Deepest gratitude to the Ministry of Education, Malaysia (MOE) and IRMI of Universiti Teknologi MARA (UiTM) for funding this research under Research Acculturation Grant Scheme (RAGS).

\section{References}

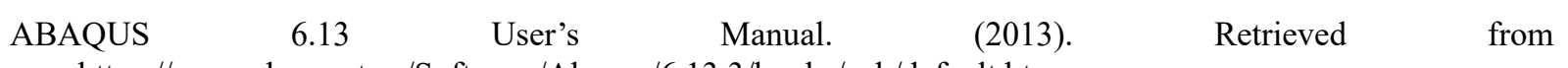
https://www.sharcnet.ca/Software/Abaqus/6.13.3/books/gsk/default.htm

Amir Radzi, B. A. G., Kee, C. S., Othman, M. Z., Bin Koslan, M. F. S., \& Zaidi, A. M. A. (2013). Impact response of multi-grooved square column. Modern Applied Science, 7(11), 12. http://dx.doi.org/10.5539/mas.v7n11p12

Bambach, M. R., Tan, G., \& Grzebieta, R. H. (2009). Steel spot-welded hat sections with perforations subjected to large deformation pure bending. Thin-Walled Structures, 47(11), 1305-1315. http://dx.doi.org/10.1016/j.tws.2009.03.010

Belingardi, G., \& Scattina, A. (2013). Experimental investigation on the bending behaviour of hybrid and steel thin walled box beams-The role of adhesive joints. International Journal of Adhesion and Adhesives, 40, 31-37. http://dx.doi.org/10.1016/j.ijadhadh.2012.08.002

Chen, W. (2001). Experimental and numerical study on bending collapse of aluminum foam-filled hat profiles. $\begin{array}{lllll}\text { International Journal of Solids and Structures, } & 38(44), & \text { 7919-7944. }\end{array}$ http://dx.doi.org/10.1016/S0020-7683(01)00094-4

Chen, W., Wierzbicki, T., \& Santosa, S. (2002). Bending collapse of thin-walled beams with ultralight filler: numerical simulation and weight optimization. Acta Mechanica, 153(3-4), 183-206. http://dx.doi.org/10.1007/BF01177451

Cimpoeru, S. J., \& Murray, N. W. (1993). The large-deflection pure bending properties of a square thin-walled tube. International Journal of Mechanical Sciences, 35(3), 247-256. http://dx.doi.org/10.1016/0020-7403(93)90079-A

Kecman, D. (1983). Bending collapse of rectangular and square section tubes. International Journal of Mechanical Sciences, 25(9), 623-636. http://dx.doi.org/10.1016/0020-7403(83)90072-3

Kim, T. H., \& Reid, S. R. (2001). Bending collapse of thin-walled rectangular section columns. Computers \& structures, 79(20), 1897-1911. http://dx.doi.org/10.1016/S0045-7949(01)00089-X

Koslan, M. F. S., Zaidi, A. M. A., Othman, M. Z., Abdullah, S., \& Thanakodi, S. (2013). The effect of mesh sizing toward deformation result in computational dynamic simulation for blast loading application. Modern Applied Science, 7(7), 23. http://dx.doi.org/10.5539/mas.v7n7p23

Santosa, S., Banhart, J., \& Wierzbicki, T. (2001). Experimental and numerical analyses of bending of foam-filled sections. Acta Mechanica, 148(1-4), 199-213. http://dx.doi.org/10.1007/BF01183678

Wierzbicki, T., Recke, L., Abramowicz, W., Gholami, T., \& Huang, J. (1994). Stress profiles in thin-walled prismatic columns subjected to crush loading-II. Bending. Computers \& structures, 51(6), 625-641. http://dx.doi.org/10.1016/S0045-7949(05)80002-1

\section{Copyrights}

Copyright for this article is retained by the author(s), with first publication rights granted to the journal.

This is an open-access article distributed under the terms and conditions of the Creative Commons Attribution license (http://creativecommons.org/licenses/by/4.0/). 